\title{
Integrated in-depth bioinformatic analysis suggests RELCH/KIAA1468, LINC02341, and $A K A P 11$ as candidate genes for ages at menarche and menopause
}

\author{
Volodymyr Dvornyk \\ College of Science and General Studies, Alfaisal University, \\ P.O.Box 50927, Riyadh, 11533, Kingdom of Saudi Arabia \\ Corresponding author: Volodymyr Dvornyk(vdvornyk@alfaisal.edu)
}

\begin{abstract}
Background: Polymorphisms of the TNFRSF11A and TNFSF11 genes were reported for their association with age at menarche (AAM) and age at natural menopause (ANM). However, the biological mechanisms underlying this association remain largely unclear. The aim of the study: This study was to determine biological processes backing the observed genetic associations. Materials and methods: Fortyfour SNPs were analyzed using in silico approach and ten publicly available online databases and tools. Results: TNFRSF11A and TNFSF11 are highly pleiotropic genes that play a role in many metabolic processes. However, among that variety, lipid metabolism and cell survival and apoptosis seem the most biologically plausible mechanisms, through which these genes contribute to AAM and ANM. The analysis identified several mechanisms underlying the previously determined association of the TNFRSF11A and TNFSF11 genes with AAM and ANM and suggested RELCH/KIAA1468, LINC02341, and AKAP11 as new candidate genes for the traits. Conclusion: The in silico analysis is a powerful approach making it possible to uncover possible metabolic pathways underlying observed genetic associations.

Keywords: bioinformatics; in silico analysis; age at menarche; age at menopause; TNFRSF11A; TNFSF11

For citation: Dvornyk V. Integrated in-depth bioinformatic analysis suggests RELCH/KIAA1468, LINC02341, and AKAP11 as candidate genes for ages at menarche and menopause. Research Results in Biomedicine. 2021;7(3):220-231. DOI: 10.18413/2658-6533-2021-7-3-0-2
\end{abstract}

Introduction. Tumor necrosis factor receptor superfamily, member $11 \mathrm{a}$ (TNFRSF11A), also known as receptor activator of nuclear factor- $\kappa \mathrm{B}(\mathrm{NF}-\kappa \mathrm{B} ; R A N K)$, and its ligand (TNFSF11 or RANKL) have been implicated in various cellular processes related to proliferation and death, immunity, and tissue development. The TNFRSF11A/TNFSF11 system is widely acknowledged as one of the key players in some primary postmenopausal disorders, such as osteoporosis [1] and cardiovascular diseases [2]. Also, these genes are expressed in mammary gland cells and were shown to con- 
trol the development of a lactating mammary gland during pregnancy [3]; that is, they play a role in the reproductive system. Several candidate gene association studies suggested that TNFRSF11A and TNFSF11 were associated with ages at menarche and menopause in different ethnic populations [4-7]. However, biological mechanisms, which underlie these associations, remain largely unclear. The exponential growth of biomolecular data and its mining into databases have provided not only a possibility of more accurate and substantiated choice of genetic markers for a study but also tools for comprehensive analysis to get deeper insights into probable functional assignments of the candidate genetic variants and mechanisms of their contribution to traits [8-10]. I took advantage of the recent advances in bioinformatics and used several online genomic databases to conduct a comprehensive in silico analysis of the TNFRSF11A and TNFSF11 polymorphisms, which were re- ported as associated with age at menarche and menopause. This bioinformatic analysis aimed to get insights into possible mechanisms of these associations.

\section{Materials and Methods}

\section{Selection of polymorphisms}

Polymorphisms for the analysis were selected based on the published results of their association with ages at menarche and/or menopause. For this purpose, PubMed was screened using terms "TNFRSF11A", "TNFSF11", "RANK", "RANKL", "menarche", and "menopause" in various combinations. The search returned four articles with relevant results. These articles reported in total 44 SNPs (reference polymorphisms hereafter) associated with ages at menarche and/or menopause in three ethnic samples: Caucasians, Chinese, and Mexicans. The list of the selected polymorphisms and the map of the genomic regions, in which they are located, are given in Table 1 and Figure 1.

Information about the analyzed SNPs

\begin{tabular}{|c|c|c|c|c|c|c|}
\hline \multirow{2}{*}{ Gene } & \multirow{2}{*}{ SNP ID } & \multirow{2}{*}{$\begin{array}{l}\text { Location in/around } \\
\text { the gene }\end{array}$} & \multicolumn{2}{|c|}{ Association } & \multirow{2}{*}{ Ethnicity } & \multirow{2}{*}{ Reference } \\
\hline & & & AAM & ANM & & \\
\hline \multirow{22}{*}{$\begin{array}{l}\text { TNFRSF11A } \\
\text { (RANK) }\end{array}$} & rs3826620 & Intron & + & + & Caucasian & [7] \\
\hline & & & + & & Chinese & [6] \\
\hline & rs 8086340 & Intron & & + & Caucasian & [7] \\
\hline & & & + & & Chinese & [6] \\
\hline & rs11665260 & Intron & + & + & Caucasian & [7] \\
\hline & rs7239261 & Intron & + & & Chinese & [6] \\
\hline & rs8094884 & Intron & + & & Chinese & [6] \\
\hline & rs8089829 & Intron & + & & Chinese & [6] \\
\hline & rs9956850 & Intron & + & & Chinese & [6] \\
\hline & rs1805034 & $\begin{array}{l}\text { Exon Missense } \\
\text { Ala/Val }\end{array}$ & + & & Chinese & [6] \\
\hline & & & + & & Chinese & [5] \\
\hline & rs 4524034 & Intron & + & & Chinese & [6] \\
\hline & rs4524035 & Intron & + & & Chinese & [6] \\
\hline & rs 12455775 & Intron & + & & Chinese & [6] \\
\hline & rs17069904 & Intron & + & & Chinese & [6] \\
\hline & rs12959396 & Intron & + & & Chinese & [6] \\
\hline & rs2981003 & $\begin{array}{l}\text { 5'-region, 5.8kb 3' of } \\
\text { KIAA1468 }\end{array}$ & + & & Chinese & [6] \\
\hline & rs2981004 & $\begin{array}{l}\text { 5'-region, } 6.2 \mathrm{~kb} 3 \text { ' of } \\
\text { KIAA1468 }\end{array}$ & + & & Chinese & [6] \\
\hline & $\mathrm{rs} 6567263$ & 5'-Region & + & & Chinese & [6] \\
\hline & rs7233197 & Intron & + & & Chinese & [6] \\
\hline & rs 4941125 & Intron & + & & Chinese & [6] \\
\hline & rs4500848 & Intron & + & & Chinese & [5] \\
\hline
\end{tabular}


End of Table 1

Information about the analyzed SNPs

\begin{tabular}{|c|c|c|c|c|c|c|}
\hline \multirow{2}{*}{ Gene } & \multirow{2}{*}{ SNP ID } & \multirow{2}{*}{$\begin{array}{c}\text { Location in/around } \\
\text { the gene }\end{array}$} & \multicolumn{2}{|c|}{ Association } & \multirow{2}{*}{ Ethnicity } & \multirow{2}{*}{ Reference } \\
\hline & & & AAM & ANM & & \\
\hline & rs6567270 & Intron & + & & Chinese & {$[5]$} \\
\hline & rs9962159 & Intron & & + & Chinese & {$[5]$} \\
\hline \multirow[t]{12}{*}{ TNFSF11 (RANKL) } & rs 12585014 & 5'-region & + & & Mexican & [4] \\
\hline & & & + & + & Caucasian & [7] \\
\hline & rs9525641 & Intron & + & + & Caucasian & [7] \\
\hline & rs2200287 & Intron & + & & Caucasian & [7] \\
\hline & rs 1054016 & 3'-UTR & + & & Caucasian & [7] \\
\hline & rs 346578 & 3'-UTR & & + & Caucasian & [7] \\
\hline & rs 3742257 & Intron & + & + & Caucasian & [7] \\
\hline & rs922996 & Intron & + & + & Caucasian & [7] \\
\hline & rs7988338 & Intron & + & + & Caucasian & [7] \\
\hline & rs2277438 & Intron & + & + & Caucasian & [7] \\
\hline & rs9525645 & Intron & + & + & Caucasian & [7] \\
\hline & rs2148073 & Intron & + & + & Caucasian & [7] \\
\hline \multirow[t]{10}{*}{ LINC02341 } & rs12874142 & 5'-region & + & & Chinese & {$[6]$} \\
\hline & rs7326472 & 5'-region & + & & Chinese & [6] \\
\hline & rs11147871 & 5'-region & + & & Chinese & {$[6]$} \\
\hline & rs9590697 & 5'-region & + & & Chinese & [6] \\
\hline & rs727243 & 5'-region & + & & Chinese & {$[6]$} \\
\hline & rs 12864265 & Intron & + & & Chinese & {$[6]$} \\
\hline & rs7316953 & Intron & + & & Chinese & {$[6]$} \\
\hline & rs 1324005 & Intron & + & & Chinese & [6] \\
\hline & rs9525625 & Intron & + & & Chinese & {$[6]$} \\
\hline & rs720824 & Intron & + & & Chinese & [6] \\
\hline \multirow[t]{9}{*}{ AKAP11 } & rs9525610 & 3'-UTR & + & & Chinese & {$[6]$} \\
\hline & rs238281 & 3'-UTR & + & & Chinese & {$[6]$} \\
\hline & rs9525613 & 3'-UTR & + & & Chinese & [6] \\
\hline & rs430586 & 3'-UTR & + & & Chinese & [6] \\
\hline & rs417768 & 3'-UTR & + & & Chinese & {$[6]$} \\
\hline & rs912100 & 3'-UTR & + & & Chinese & [6] \\
\hline & rs 17063218 & 3'-UTR & + & & Chinese & [6] \\
\hline & rs17522044 & 3'-UTR & + & & Chinese & [6] \\
\hline & rs238270 & 3'-UTR & + & & Chinese & [6] \\
\hline
\end{tabular}

(a)

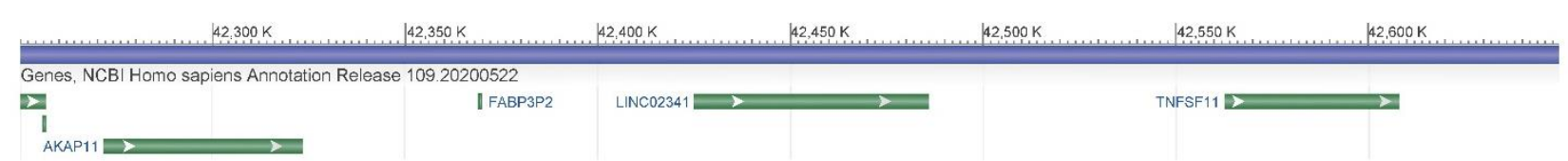

Chr13

(b)

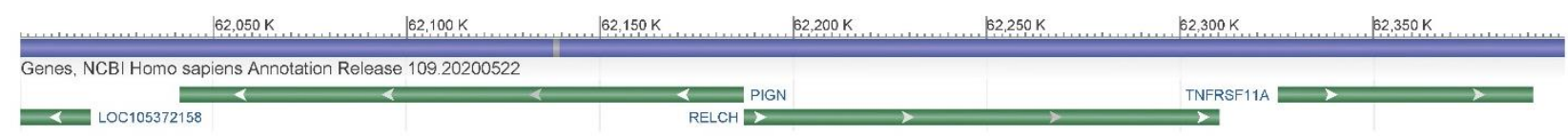

Chr18

Fig. 1. Maps of the genomic regions where the analyzed SNPs and genes are located. 


\section{Bioinformatic analysis}

In total ten bioinformatics tools were employed for the analyses.

The effect of non-synonymous SNPs on the protein function was analyzed using SIFT (https://sift.bii.a-star.edu.sg/) [11].

The integrated online tool, HaploReg v4.1 [12] was used to identify polymorphisms in strong linkage disequilibrium (LD) $\left(\mathrm{r}^{2} \geq\right.$ 0.8 ) with the AAM- and/or ANM-associated ones and to analyze them for their functional significance (chromatin states, motifs changes, protein interactions, regulatory potential, and eQTLs). The analysis was conducted separately for Caucasian and Chinese ethnicities using the data of the European and Asian populations from the 1000 Genomes Project Phase.

In addition to HaploReg (v4.1), three other databases were used to analyze regulatory effects of the polymorphisms: RegulomeDB (Version (http://regulome.stanford.edu/) rSNPBase (http://rsnp.psych.ac.cn/index.do) [14], and SNP Function Prediction (FuncPred)

(https://snpinfo.niehs.nih.gov/snpinfo/snpfunc .html) [15], and GeneCards (https://www.genecards.org/) [16].

The effect of the 44 candidate SNPs for AAM and ANM on gene expression level (cis- and trans-eQTL) was estimated in peripheral blood using the Blood eQTL browser (http://genenetwork.nl/bloodeqtlbrowser/)

[17], and in other organs and tissues using the GTExportal data (http://www.gtexportal.org/) as of $07 / 27 / 2020$. The false discovery rate (FDR) $\leq 0.05$ was applied as the significance level.

The functional significance of the candidate genes for AAM in the various biological pathways was studied using the Gene Ontology Resource tools available at http://geneontology.org [18]. The results of multiple comparisons were adjusted with the FDR $<0.05$. The gene interaction networks were constructed using GeneMANIA (version 3.5.0) [19] available at http://genemania.org.

\section{Results}

Genomic location of the SNPs

First of all, 21 out of the 44 reference SNPs previously annotated to the regions of the TNFRSF11A and TNFSF11 genes could also be mapped to the regions of the other genes (Table 1). Ten reference SNPs were located in the region of the LINC02341 gene, five of them in the introns. Nine variants were located in the 3'-UTR of the AKAP11 gene. Two SNPs, rs2981003 and rs2981004, were located in the 3'-UTR of the RELCH/KIAA1468 gene.

Non-synonymous SNPs

Only one of all analyzed SNPs, rs1805034 in the TNFRSF11A gene, was missense. It results in an $\mathrm{Ala} / \mathrm{Val}$ replacement in the respective protein. The replacement has SIFT Score $=1$ and prediction value "tolerated".

SNPs in strong LD with the reference polymorphisms

The query against the HaploReg database returned in a total of 348 (224 unique) SNPs linked to the reference ones of the TNFRSF11A gene and 779 (322 unique) SNPs linked to the reference loci of the TNFSF 11 gene (Supplementary Table 1). The SNP association and linkage patterns were quite different between European and Asian populations. Specifically, two SNPs of the TNFRSF11A gene, rs3826620 and rs8086340, were associated with AAM and/or ANM in both Caucasians and Chinese [6, 7]. However, the HaploReg analysis returned no SNPs linked to rs3826620 in Europeans vs eight SNPs in Asians. In total, six loci were linked to the three reference SNPs in the European population and 218 were linked to the 19 reference SNPs in the Asian population. Out of these 224 unique SNPs, only three were shared between the European and Asian populations. Quite a few SNPs in the Asian population were located at/near the RELCH/KIAA1468 and PIGN genes (Supplementary Table 1).

Even more striking ethnicity-related differences were observed for the TNFSF 11 gene polymorphisms: no shared SNPs in Europeans and Asians. In the Asian population, more 
than half reference and linked to them polymorphisms were located at/near the AKAP11 gene (Supplementary Table 1).

Regulatory effects

The results of the regulatory effect analysis are shown in Supplementary tables 1 and 2. They suggest that all reference SNPs can produce various regulatory effects, albeit to a different extent. For example, rs8086340 of the TNFRSF11A gene displays histone marks associated with promoters in six tissues and enhancers in 14 tissues, located in the DNase-1 hypersensitive region in 21 tissues, binding region for six proteins, and altered motif for the Foxm1 transcription factor (Supplementary Table 1).

Table 2

Effect of the reference AAM- and ANM-associated SNPs on the gene expression (cis-eQTL) in peripheral blood according to the Blood eQTL browser [17]

\begin{tabular}{|c|c|c|c|c|}
\hline SNP & Gene/Region & Gene Expressed & $P$ & FDR* \\
\hline rs3826620 & TNFRSF11A & RELCH/KIAA1468 & $4.7 * 10^{-9}$ & 0.00 \\
\hline rs 8086340 & TNFRSF11A & RELCH/KIAA1468 & $6.9 * 10^{-5}$ & 0.03 \\
\hline rs7239261 & TNFRSF11A & RELCH/KIAA1468 & $3.9 * 10^{-5}$ & 0.02 \\
\hline rs7233197 & TNFRSF11A & RELCH/KIAA1468 & $3.1 * 10^{-9}$ & 0.00 \\
\hline rs 4941125 & TNFRSF11A & RELCH/KIAA1468 & $3.7 * 10^{-6}$ & 0.00 \\
\hline rs9962159 & TNFRSF11A & RELCH/KIAA1468 & $7.3 * 10^{-5}$ & 0.03 \\
\hline rs12874142 & $80 \mathrm{~kb} 3^{\prime}$ of $A K A P 11$ & AKAP11 & $6.5 * 10^{-5}$ & 0.03 \\
\hline rs9525625 & $117 \mathrm{~kb} 3^{\prime}$ of AKAP11 & AKAP11 & $1.1 * 10^{-6}$ & 0.00 \\
\hline rs238281 & 13kb 3' of AKAPII & AKAP11 & $1.9 * 10^{-32}$ & 0.00 \\
\hline rs9525613 & $21 \mathrm{~kb} 3^{\prime}$ of $A K A P 11$ & AKAP11 & $2.6 * 10^{-8}$ & 0.00 \\
\hline rs430586 & $23 \mathrm{~kb} 3^{\prime}$ of $A K A P 11$ & AKAP11 & $1.0 * 10^{-21}$ & 0.00 \\
\hline rs417768 & $23 \mathrm{~kb} 3^{\prime}$ of $A K A P 11$ & AKAP11 & $1.4 * 10^{-21}$ & 0.00 \\
\hline rs912100 & $24 k b 3^{\prime}$ of $A K A P 11$ & AKAP11 & $6.4 * 10^{-30}$ & 0.00 \\
\hline rs 238270 & $36 \mathrm{~kb} 3^{\prime}$ of $A K A P 11$ & AKAP11 & $1.4 * 10^{-20}$ & 0.00 \\
\hline
\end{tabular}

Note: * FDR, False Discovery Rate

\section{Expression QTLs}

Several reference SNPs appeared to have a significant $c i s$-eQTL effect on the expression of five genes, RELCH/KIAA1468, PIGN, AKAP11, TNFRSF11A, and TNFSF11, in various tissues and organs (Tables 2 and 3 ).

Pathway analysis

This analysis was conducted for TNFRSF11A and TNFSF11 (because they were originally reported as associated with AAM and/or ANM), LINC02341 (because several reference polymorphisms were mapped to this gene), and RELCH/KIAA1468, PIGN, AKAP11 (because the expression of these genes might be affected by some reference SNPs according to the eQTL analysis).

According to the results of the PANTHER overrepresentation test, the TNFRSF11A and TNFSF11 genes are involved in a broad range of biological processes, including regulation of ERK1 and ERK2 cascade, secretion of prostaglandins, bone remodeling, and mammary gland development (Supplementary Table 3). Apart from these two, AKAP11 was suggested to contribute to the organism's homeostasis (Supplementary Table 3). No data was found for RELCH/KIAA1468, PIGN, and LINC02341.

The gene-gene interaction network inferred using GeneMANIA (Figure 2) suggested that the major contribution $(64.32 \%)$ came from physical interactions between the proteins, followed by co-expression (25.88\%), co-localization $(5.61 \%)$, and common pathways $(4.19 \%)$. 
Beginning of Table 3

Effect of the reference AAM- and ANM-associated SNPs on the gene expression (cis-eQTL) in various tissues according to the GTEx browser

\begin{tabular}{|c|c|c|c|c|}
\hline SNP & Gene/Region & Gene Expressed & Effect & Tissue \\
\hline rs3826620 & TNFRSF11A & RELCH/KIAA1468 & Down & Nerve-tibial \\
\hline rs11665260 & TNFRSF11A & RELCH/KIAA1468 & Down & Skin - sun exposed (lower leg) \\
\hline rs8094884 & TNFRSF11A & RELCH/KIAA1468 & $\mathrm{Up}$ & Skin - sun exposed (lower leg) \\
\hline rs8089829 & TNFRSF11A & RELCH/KIAA1468 & Down & Testis, nerve - tibial \\
\hline \multirow[t]{2}{*}{ rs9956850 } & TNFRSF11A & RELCH/KIAA1468 & Up & Adipose-subcutaneous \\
\hline & & PIGN & Down & Aorta, coronary artery, adipose tissue, thyroid \\
\hline \multirow[t]{2}{*}{ rs17069904 } & $23 k b 3^{\prime}$ of $A K A P 11$ & TNFRSF11A & Down & Esophagus - mucosa \\
\hline & & PIGN & $\mathrm{Up}$ & Adipose-subcutaneous, lung, muscle-skeletal \\
\hline rs12959396 & $24 \mathrm{~kb} 3^{\prime}$ of $A K A P 11$ & RELCH/KIAA1468 & Down & Testis \\
\hline \multirow[t]{2}{*}{ rs2981003 } & $36 \mathrm{~kb} 3^{\prime}$ of $A K A P 11$ & TNFRSF11A & $\mathrm{Up}$ & $\begin{array}{l}\text { Skin, esophagus-mucosa, brain, lung, mammary tissue, pancreas, pituitary, } \\
\text { thyroid }\end{array}$ \\
\hline & & $P I G N$ & Down & $\begin{array}{l}\text { Adipose-subcutaneous, esophagus-mucosa, brain, lung, muscle-skeletal, } \\
\text { thyroid, artery-tibial, nerve-tibial }\end{array}$ \\
\hline rs2981004 & $6.2 \mathrm{~kb} 3^{\prime}$ of KIAA1468 & TNFRSF11A & Up & $\begin{array}{l}\text { Skin, esophagus-mucosa, brain, lung, mammary tissue, pancreas, pituitary, } \\
\text { thyroid }\end{array}$ \\
\hline rs6567263 & $4.9 \mathrm{~kb} 5$ ' of TNFRSF11A & $P I G N$ & Down & $\begin{array}{l}\text { Adipose-subcutaneous, esophagus-mucosa, brain, lung, muscle-skeletal, } \\
\text { thyroid, artery-tibial, nerve-tibial }\end{array}$ \\
\hline \multirow[t]{2}{*}{ rs7233197 } & TNFRSF11A & RELCH/KIAA1468 & Down & $\begin{array}{l}\text { Skin, esophagus-mucosa, brain, lung, mammary tissue, pancreas, pituitary, } \\
\text { thyroid, nerve-tibial }\end{array}$ \\
\hline & & $P I G N$ & Down & $\begin{array}{l}\text { Adipose-subcutaneous, esophagus-mucosa, brain, lung, muscle-skeletal, } \\
\text { thyroid, artery-tibial, nerve-tibial }\end{array}$ \\
\hline \multirow[t]{2}{*}{ rs4941125 } & TNFRSF11A & TNFRSF11A & Up & Esophagus-mucosa, skin, thyroid \\
\hline & & $P I G N$ & Down & Skin, thyroid, adipose-subcutaneous, small intestine-ileum \\
\hline \multirow[t]{2}{*}{ rs4500848 } & TNFRSF11A & RELCH/KIAA1468 & Down & Nerve-tibial, adipose-subcutaneous, testis \\
\hline & & $P I G N$ & Down & Skin, brain \\
\hline \multirow[t]{2}{*}{ rs9962159 } & TNFRSF11A & TNFRSF11A & Up & Skin, thyroid \\
\hline & & PIGN & Down & Skin, thyroid, adipose-subcutaneous \\
\hline \multirow[t]{2}{*}{ rs12874142 } & $80 \mathrm{~kb} 3^{\prime}$ of $A K A P 11$ & TNFSF11 & $\mathrm{Up}$ & Esophagus-mucosa \\
\hline & & $A K A P 11$ & Up & Esophagus-muscularis, brain, skin \\
\hline \multirow[t]{2}{*}{ rs9590697 } & 97kb 3' of AKAP11 & TNFSF11 & Up & Esophagus-mucosa \\
\hline & & $A K A P 11$ & Up & Esophagus-muscularis, skin \\
\hline \multirow[t]{2}{*}{ rs727243 } & 98kb 3' of AKAPl1 & TNFSF11 & Up & Esophagus-mucosa \\
\hline & & $A K A P 11$ & $\mathrm{Up}$ & Esophagus-muscularis \\
\hline
\end{tabular}


End of Table 3

Effect of the reference AAM- and ANM-associated SNPs on the gene expression (cis-eQTL) in various tissues according to the GTEx browser

\begin{tabular}{|c|c|c|c|c|}
\hline SNP & Gene/Region & Gene Expressed & Effect & Tissue \\
\hline \multirow[t]{2}{*}{ rs12864265 } & $117 \mathrm{~kb} 3^{\prime}$ of $A K A P 11$ & TNFSF11 & Up & Esophagus-mucosa \\
\hline & & $A K A P 11$ & $\mathrm{Up}$ & Esophagus-muscularis, skin \\
\hline \multirow[t]{2}{*}{ rs7316953 } & $119 \mathrm{~kb} \mathrm{5}$ of TNFSF11 & TNFSF11 & Down & Esophagus-mucosa \\
\hline & & $A K A P 11$ & Down & Esophagus-muscularis \\
\hline \multirow[t]{2}{*}{ rs1324005 } & $119 \mathrm{~kb} 5^{\prime}$ of TNFSF11 & TNFSF11 & Up & Esophagus-mucosa \\
\hline & & $A K A P 11$ & $\mathrm{Up}$ & Esophagus-muscularis, skin \\
\hline rs9525625 & $119 \mathrm{~kb} \mathrm{5}$ of TNFSF11 & $A K A P 11$ & Down & Esophagus-mucosa, esophagus-muscularis, brain \\
\hline \multirow[t]{2}{*}{ rs720824 } & $119 \mathrm{~kb} 5^{\prime}$ of $T N F S F 11$ & TNFSF11 & Down & Esophagus-mucosa \\
\hline & & $A K A P 11$ & Down & Esophagus-muscularis \\
\hline rs238281 & $13 \mathrm{~kb} 3^{\prime}$ of $A K A P 11$ & $A K A P 11$ & $\mathrm{Up}$ & $\begin{array}{l}\text { Artery, brain, colon, esophagus-mucosa, esophagus-muscularis, nerve- } \\
\text { tibial, adipose-subcutaneous }\end{array}$ \\
\hline rs9525613 & $21 \mathrm{~kb} 3^{\prime}$ of $A K A P 11$ & $A K A P 11$ & $\mathrm{Up}$ & Artery-tibial \\
\hline rs430586 & $23 k b 3^{\prime}$ of $A K A P 11$ & $A K A P 11$ & Up/Down & $\begin{array}{l}\text { Esophagus-mucosa, esophagus-muscularis, brain, adipose-subcutaneous, } \\
\text { heart, muscle-skeletal }\end{array}$ \\
\hline rs417768 & $23 k b 3^{\prime}$ of $A K A P 11$ & $A K A P 11$ & Up/Down & $\begin{array}{l}\text { Esophagus-mucosa, esophagus-muscularis, brain, adipose-subcutaneous, } \\
\text { heart, muscle-skeletal }\end{array}$ \\
\hline rs912100 & $24 \mathrm{~kb} 3^{\prime}$ of $A K A P 11$ & $A K A P 11$ & Up/Down & $\begin{array}{l}\text { Esophagus-mucosa, esophagus-muscularis, brain, adipose-subcutaneous, } \\
\text { heart, muscle-skeletal, vagina, lung, colon, nerve-tibial }\end{array}$ \\
\hline rs17063218 & $25 \mathrm{~kb} 3^{\prime}$ of $A K A P 11$ & $A K A P 11$ & Up/Down & $\begin{array}{l}\text { Esophagus-mucosa, esophagus-muscularis, brain, adipose-subcutaneous, } \\
\text { heart, muscle-skeletal, vagina, lung, colon, nerve-tibial }\end{array}$ \\
\hline rs17522044 & $26 \mathrm{~kb} 3^{\prime}$ of $A K A P 11$ & $A K A P 11$ & Up & $\begin{array}{l}\text { Esophagus-mucosa, esophagus-muscularis, heart, muscle-skeletal, nerve- } \\
\text { tibial, artery-tibial }\end{array}$ \\
\hline rs 238270 & $36 \mathrm{~kb} 3^{\prime}$ of $A K A P 11$ & $A K A P 11$ & Up/Down & $\begin{array}{l}\text { Esophagus-mucosa, esophagus-muscularis, brain, adipose-subcutaneous, } \\
\text { muscle-skeletal, nerve-tibial }\end{array}$ \\
\hline
\end{tabular}




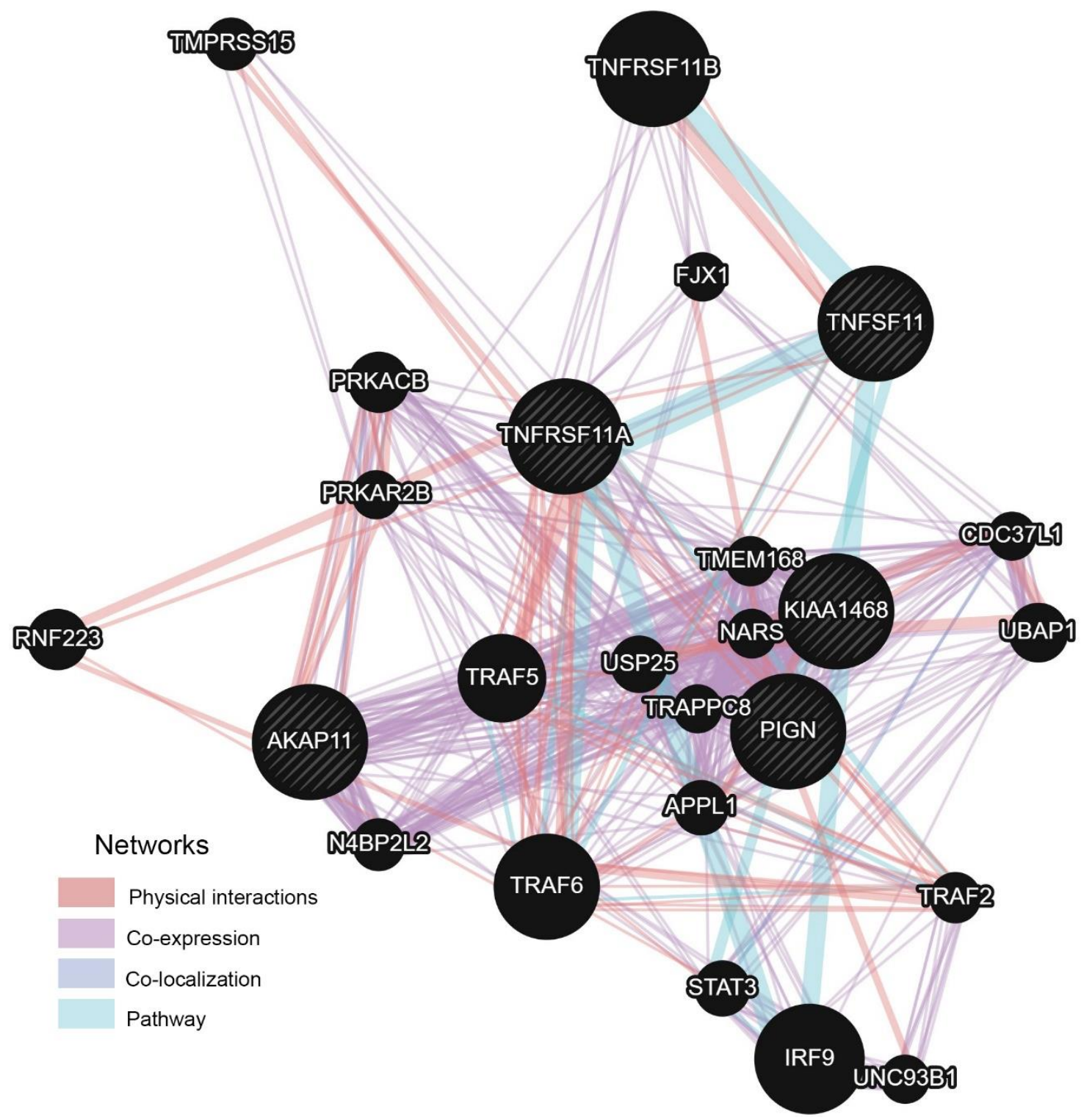

Fig. 2. The interaction networks of the candidate genes for age at menarche and natural menopause inferred using GeneMANIA. The candidate genes for the traits determined in the present study are cross-shaded

Discussion. This study provides evidence that, in addition to the TNFRSF11A and TNFSF 11 genes previously reported as associated with AAM and/or ANM, four other genes might be associated with these traits.

The LINC02341 gene belongs to the class of long non-coding RNAs. There is not much information about LINC02341 in public databases. Although long non-coding RNAs have not been studied well, there is a growing body of evidence that they are involved in transcriptional regulation [20]. Indeed, according to the GeneHancer database [21], LINC02341 harbors enhancers for six genes, including TNFSF 11 and $A K A P 11$, and binding sites for 76 transcription factors. The expression of the gene is relatively low and was documented in several tissues and organs, including lymph nodes, kidneys, placenta, and others [22]. The reference SNP, rs9525625, which is an intronic variant of the gene, was reported as a risk factor of inflammatory bowel disease [23].

The regions of two genes, RELCH/KIAA1468 and AKAP11, also harbored several reference SNPs associated with AAM (Table 1). Besides, quite a few genetic variants in these genes were linked to the reference pol- 
ymorphisms (Supplementary Table 1). These results suggested that the above genes might also contribute to the above trait.

RELCH (RAB11 binding and LisH domain, coiled-coil and HEAT repeatcontaining, alias KIAA1468) encodes a protein playing a key role in intracellular cholesterol distribution [24]. The gene is ubiquitously expressed in human tissues and organs, including endocrine glands, endometrium, and ovaries [22]. The results of the GeneMANIA analysis suggested that this gene was coexpressed with TNFRSF11A, AKAP11, and PIGN (Figure 2).

A product of AKAP11, A-kinase anchoring protein 11, belongs to the protein family whose members, despite the diverse structure, have the same function of binding to the regulatory subunit of protein kinase A and targeting the enzyme to specific locations in the cell. It has similar to RELCH expression patterns [22] but is not co-expressed with TNFRSF11A and PIGN (Figure 2).

The PIGN gene encodes ethanolamine phosphate transferase, a key element of glycosylphosphatidylinositol-anchor biosynthesis. Mutations in the gene were associated with multiple congenital anomalieshypotonia-seizures syndrome [25]. The gene is co-expressed with TNFRSF11A and RELCH (Figure 2).

RELCH and AKAPII are pleiotropic genes and were associated with multiple traits, including those related to menarche and menopause (e.g., bone phenotypes, obesity, development, etc.) [26, 27]. There is ample evidence that the above phenotypes have a shared genetic basis with AAM and ANM (see e.g., $[6,7,28]$. Together with the results of the in silico analysis of the present study, it suggests that RELCH/KIAA1468, LINC02341, and $A K A P 11$ may be candidate genes for AAM and/or ANM. This assumption is biologically plausible too.

A possible contribution of PIGN to AAM and/or ANM looks less obvious, largely due to the lack of data about the association of this gene with menarche- and menopauserelated phenotypes. On the other hand, according to GeneHancer, this gene harbors binding sites of multiple transcription factors targeting the expression of RELCH and TNFRSF11A. Furthermore, given the involvement of this gene in the basic cellular and developmental processes [29] and tight linkage to the AAM-associated loci (Supplementary Table 1), the above possibility could not be ruled out.

The results of the Gene Ontology and GeneMANIA analyses (Supplementary tables 3,4 , Figure 2) suggested that the contribution of TNFRSF11A and TNFSF11 to menarche and menopause timing is likely multifaceted. The TNFRSF11A/TNFSF11/TNFRSF11B $(R A N K / R A N K L / O P G)$ signaling pathway has been widely acknowledged as a key player in bone remodeling [1]. Apart from this, the system plays an important role in the progesterone-driven proliferation of the mammary gland epithelium and the risk of breast cancer [30]. One of the possible ways through which TNFRSF11A can affect AAM and ANM is an interaction with TRAF2, a key element in the control of cell survival and apoptosis [31]. Involvement in the metabolism of lipids may be one more important biological mechanism of the AAM- and ANM-related role of TNFRSF11A. The relationship between obesity and AAM/ANM has been well documented $[32,33]$. Arachidonic acid/prostaglandin E2 axis was implicated in uterine epithelium cell death induced by menopause [34]. The fatty acid composition was shown to be related to the menopausal status [35].

The lack of the GO Ontology data about RELCH/KIAA1468, PIGN, and LINC02341 may suggest that their role in metabolic pathways is still poorly studied. On the other hand, there is extensive evidence about coexpression of RELCH/KIAAI468 and PIGN with many genes, including those involved in the control of the basic cellular processes, e.g., cell proliferation [36] (Supplementary Table 4).

In general, a degree of gene pleiotropy seems to be inversely related to the relative contribution of the gene to the trait. Given that most genes in the human genome are pleiotropic [37], the expected contribution of each of them to a particular trait is quite mod- 
est. Therefore, highly pleiotropic genes have a small effect size and often yield false negative results in GWAS unless their contribution to a particular trait is above the average for other traits (e.g., TNFRSF11A/TNFSF11 contribution to bone remodeling).

The present study also sheds light on the frequently observed inconsistencies in associated polymorphisms and unsuccessful attempts to replicate candidate loci in different ethnic populations. Previous studies suggested that differences in population genetic structure might underlie the above disparities [38, 39]. The results of the present study suggest that, in addition to the allele frequencies, population-specific LD patterns are another important factor.

Conclusion. The in silico analysis of the TNFRSF11A and TNFSF11 polymorphisms previously reported for association with AAM and/or ANM suggested RELCH/KIAA1468, LINC02341, and AKAP11 genes as candidates for the traits. While this assumption is biologically plausible, candidate gene association studies are needed to verify it. In summary, the present study demonstrates that the in-depth analysis of rapidly expanding biological databases may provide new insights into possible factors and mechanisms underlying the observed association of genetic markers with a trait.

\section{Financial support}

No financial support has been provided for this work.

\section{Conflict of interests}

The author has no conflict of interest to declare.

\section{References}

1. Boyce BF, Xing L. Functions of RANKL/RANK/OPG in bone modeling and remodeling. Archives of Biochemistry and Biophysics. 2008;473(2):139-46. DOI: https://doi.org/10.1016/j.abb.2008.03.018

2. Harper E, Forde H, Davenport C, et al. Vascular calcification in type-2 diabetes and cardiovascular disease: Integrative roles for OPG, RANKL and TRAIL. Vascular Pharmacology.
2016;82:30-40.

DOI:

https://doi.org/10.1016/j.vph.2016.02.003

3. Theill LE, Boyle WJ, Penninger JM. RANK-L and RANK: T cells, bone loss, and mammalian evolution. Annual Review of Immunology. 2002;20:795-823. DOI: https://doi.org/10.1146/annurev.immunol.20.1003 01.064753

4. Casas-Avila L, Ponce de Leon-Suarez V, Penaloza-Espinosa RI, et al. The RANKL rs12585014 polymorphism is associated with age at menarche in postmenopausal women with hip fracture. Gynecological Endocrinology. 2018:34(12):1031-1034. DOI: https://doi.org/10.1080/09513590.2018.1481943

5. Duan P, Wang ZM, Liu J, et al. Gene polymorphisms in $R A N K L / R A N K / O P G$ pathway are associated with ages at menarche and natural menopause in Chinese women. BMC Women's Health. 2015;15:32. DOI: https://doi.org/10.1186/s12905-015-0192-3

6. Pan R, Liu YZ, Deng HW, et al. Association analyses suggest the effects of RANK and RANKL on age at menarche in Chinese women. Climacteric. 2012;15(1):75-81. DOI: https://doi.org/10.3109/13697137.2011.587556

7. Lu Y, Liu P, Recker RR, et al. TNFRSF11A and TNFSF11 are associated with age at menarche and natural menopause in white women. Menopause. 2010;17(5):1048-1054. DOI: https://doi.org/10.1097/gme.0b013e3181d5d523

8. Chen CY, Chang IS, Hsiung CA, et al. On the identification of potential regulatory variants within genome wide association candidate SNP sets. BMC Medical Genomics. 2014;7:34. DOI: https://doi.org/10.1186/17558794-7-34

9. Herman MA, Rosen ED. Making biological sense of GWAS data: lessons from the FTO locus. Cell Metabolism. 2015;22(4):538-9. DOI: https://doi.org/10.1016/j.cmet.2015.09.018

10. Reshetnikov EA. Study of associations of candidate genes differentially expressing in the placenta with the development of placental insufficiency with fetal growth restriction. Research Results in Biomedicine. 2020;6(3):338349. Russian. DOI: https://doi.org/10.18413/26586533-2020-6-3-0-5

11. Sim NL, Kumar P, Hu J, et al. SIFT web server: predicting effects of amino acid substitutions on proteins. Nucleic Acids Research. 2012;40(W1):W452-W457.

DOI: https://doi.org/10.1093/nar/gks539 
12. Ward LD, Kellis M. HaploReg: a resource for exploring chromatin states, conservation, and regulatory motif alterations within sets of genetically linked variants. Nucleic Acids Research. 2012;40(D1):D930-D934. DOI: https://doi.org/10.1093/nar/gkr917

13. Boyle AP, Hong EL, Hariharan M, et al. Annotation of functional variation in personal genomes using RegulomeDB. Genome Research. 2012;22:1790-1797.

DOI:

https://doi.org/10.1101/gr.137323.112

14. Guo L, Du Y, Chang $\mathrm{S}$, et al. rSNPBase: a database for curated regulatory SNPs. Nucleic Acids Research. 2014;42(D1):D1033-D1039. DOI: https://doi.org/10.1093/nar/gkt1167

15. Xu Z, Taylor JA. SNPinfo: integrating GWAS and candidate gene information into functional SNP selection for genetic association studies. Nucleic Acids Research. 2009;37(suppl_2):W600-W605.

DOI: https://doi.org/10.1093/nar/gkp290

16. Stelzer G, Rosen N, Plaschkes I, et al. The GeneCards Suite: from gene data mining to disease genome sequence analyses. Current Protocols in Bioinformatics. 2016;54:1.30.11.30.33. DOI: https://doi.org/10.1002/cpbi.5

17. Westra H-J, Peters MJ, Esko T, et al. Systematic identification of trans eQTLs as putative drivers of known disease associations. Nature Genetics. 2013;45(10):1238-1243. DOI: https://doi.org/10.1038/ng.2756

18. The Gene Ontology Consortium. The Gene Ontology Resource: 20 years and still GOing strong. Nucleic Acids Research. 2019;47(D1):D330-D338.

DOI: https://doi.org/10.1093/nar/gky1055

19. Warde-Farley D, Donaldson SL, Comes O, et al. The GeneMANIA prediction server: biological network integration for gene prioritization and predicting gene function. Nucleic Acids Research. 2010;38(suppl_2):W214W220. DOI: https://doi.org/10.1093/nar/gkq537

20. Ma L, Cao J, Liu L, et al. LncBook: a curated knowledgebase of human long non-coding RNAs. Nucleic Acids Research. 2019;47(D1):D128-D134. DOI: https://doi.org/10.1093/nar/gky960

21. Fishilevich S, Nudel R, Rappaport N, et al. GeneHancer: genome-wide integration of enhancers and target genes in GeneCards. Database. 2017;2017:bax028. DOI: https://doi.org/10.1093/database/bax028
22. Fagerberg L, Hallstrom BM, Oksvold $\mathrm{P}$, et al. Analysis of the human tissue-specific expression by genome-wide integration of transcriptomics and antibody-based proteomics. Molecular and Cellular Proteomics. 2014;13(2):397-406. DOI: https://doi.org/10.1074/mcp.M113.035600

23. Liu JZ, van Sommeren S, Huang H, et al. Association analyses identify 38 susceptibility loci for inflammatory bowel disease and highlight shared genetic risk across populations. Nature Genetics. 2015;47(9):979-986. DOI: https://doi.org/10.1038/ng.3359

24. Sobajima T, Yoshimura SI, Maeda T, et al. The Rab11-binding protein RELCH/KIAA1468 controls intracellular cholesterol distribution. Journal of Cell Biology. 2018;217(5):1777-1796.

DOI: https://doi.org/10.1083/jcb.201709123

25. Maydan G, Noyman I, Har-Zahav A, et al. Multiple congenital anomalies-hypotoniaseizures syndrome is caused by a mutation in PIGN. Journal of Medical Genetics. 2011;48(6):383-9. DOI: http://dx.doi.org/10.1136/jmg.2010.087114

26. Tachmazidou I, Suveges D, Min JL, et al. Whole-Genome Sequencing Coupled to Imputation Discovers Genetic Signals for Anthropometric Traits. American Journal of Human Genetics. 2017;100(6):865-884. DOI: https://doi.org/10.1016/j.ajhg.2017.04.014

27. Zhang L, Choi HJ, Estrada K, et al. Multistage genome-wide association metaanalyses identified two new loci for bone mineral density. Human Molecular Genetics. 2014;23(7):1923-33. DOI: https://doi.org/10.1093/hmg/ddt575

28. Liu PY, Lu Y, Recker RR, et al. ALOX12 gene is associated with the onset of natural menopause in white women. Menopause. 2010;17(1):152-156.

DOI: https://doi.org/10.1097/gme.0b013e3181b63c68

29. Ohba C, Okamoto N, Murakami Y, et al. PIGN mutations cause congenital anomalies, developmental delay, hypotonia, epilepsy, and progressive cerebellar atrophy. Neurogenetics. 2014;15(2):85-92.

DOI: https://doi.org/10.1007/s10048-013-0384-7

30. Infante M, Fabi A, Cognetti F, et al. RANKL/RANK/OPG system beyond bone remodeling: involvement in breast cancer and clinical perspectives. Journal of Experimental and Clinical Cancer Research. 2019;38(1):12. DOI: https://doi.org/10.1186/s13046-018-1001-2 
31. Zhang L, Blackwell K, Shi Z, et al. The RING domain of TRAF2 plays an essential role in the inhibition of TNFalpha-induced cell death but not in the activation of NF-kappaB. Journal of Molecular Biology. 2010;396(3):52839.

DOI:

https://doi.org/10.1016/j.jmb.2010.01.008

32. Biro FM, Khoury P, Morrison JA. Influence of obesity on timing of puberty. International Journal of Andrology. 2006;29(1):272-277. DOI: https://doi.org/10.1111/j.1365-2605.2005.00602.x

33. Lovejoy JC. The menopause and obesity. Primary Care - Clinics in Office Practice. 2003;30(2):317-325. DOI: https://doi.org/10.1016/S0095-4543(03)00012-5

34. Zhou S, Zhao L, Yi $\mathrm{T}$, et al. Menopause-induced uterine epithelium atrophy results from arachidonic acid/prostaglandin E2 axis inhibition-mediated autophagic cell death. Scientific Reports. 2016;6:31408. DOI: https://doi.org/10.1038/srep31408

35. Stark KD, Park EJ, Holub BJ. Fatty acid composition of serum phospholipid of premenopausal women and postmenopausal women receiving and not receiving hormone replacement therapy. Menopause. 2003;10(5):448-55. DOI: https://doi.org/10.1097/01.GME.0000059861.936 $39.1 \mathrm{~A}$

36. Xu J, Su Z, Ding Q, et al. Inhibition of proliferation by knockdown of transmembrane (TMEM) 168 in glioblastoma cells via suppression of Wnt/beta-catenin pathway.
Oncology Research. 2019;27(7):819-826. DOI: https://doi.org/10.3727/096504018X15478559215 014

37. Watanabe K, Stringer S, Frei O, et al. A global overview of pleiotropy and genetic architecture in complex traits. Nature Genetics. 2019;51(9):1339-1348.

DOI: https://doi.org/10.1038/s41588-019-0481-0

38. Dvornyk V, Liu PY, Long JR, et al. Contribution of genotype and ethnicity to bone mineral density variation in Caucasians and Chinese: a test for five candidate genes for bone mass. Chinese Medical Journal. 2005;118(15):1235-1244.

39. Dvornyk V, Liu XH, Shen $\mathrm{H}$, et al. Differentiation of Caucasians and Chinese at bone mass candidate genes: implication for ethnic difference of bone mass. Ann Hum Genet. 2003;67(Pt 3):216-27. DOI: https://doi.org/10.1046/j.1469-1809.2003.00037.x

Received 15 April 2021

Revised 30 May 2021

Accepted 21 June 2021

Information about the author Volodymyr Dvornyk, PhD, Associate Professor at the Department of Life Sciences, College of Science and General Studies, Alfaisal University, Riyadh, Kingdom of Saudi Arabia, E-mail: vdvornyk@alfaisal.edu, ORCID: https://orcid.org/0000-0002-2535-103X. 